\title{
ENTRE O INATO E O APRENDIDO: O CONCEITO DE DESENVOLVIMENTO INFANTIL DE CRIANÇAS DE 1 A 3 ANOS DE IDADE
}

\section{BETWEEN THE INATISM AND THE LEARNING: THE CHILD DEVELOPMENT CONCEPT THE 1 TO 3 YEARS OLD CHILDREN}

\section{Luciana Macalossi ${ }^{1}$ \\ Bruna Carolini de Bona ${ }^{2}$}

\begin{abstract}
RESUMO: Esta pesquisa, fundamentada na teoria histórico-cultural, de abordagem qualitativa, busca compreender a concepção das professoras pedagogas sobre 0 desenvolvimento infantil de crianças de 1 a 3 anos de idade. Os dados da pesquisa de campo foram analisados por meio de questionário aberto com 14 professoras pedagogas dos 3 centros de educação infantil do Município de Balneário Arroio do Silva/SC. O tema entre o inato e o aprendido: o conceito de desenvolvimento infantil de crianças de 1 a 3 anos de idade objetivou, de forma descritiva: 1) compreender a concepção de desenvolvimento infantil das professoras pesquisadas; 2) identificar, na perspectiva das professoras pedagogas, a relação entre desenvolvimento e aprendizagem das crianças de 1 a 3 anos de idade e 3) aprofundar a concepção de desenvolvimento infantil na teoria histórico-cultural. Os resultados da pesquisa indicam que a compreensão das professoras pedagogas acerca do desenvolvimento infantil reflete, com maior saliência, o inatismo e o construtivismo, de modo diferente das bases curriculares que orientam a rede de ensino. A análise evidencia, ademais, a realização de uma correlação entre desenvolvimento e aprendizagem, revelando uma percepção de sua relevância. Porém, a maioria das docentes afirma que o desenvolvimento biológico da criança precisa anteceder a aprendizagem. Por isso, este estudo evidencia a relação orgânica entre aprendizagem e desenvolvimento, a partir de um embasamento na teoria histórico-cultural, a qual enfatiza a importância do ensino para o desenvolvimento infantil. Compreende-se, a criança, nessa perspectiva, como sujeito ativo e atuante no mundo, por meio de um processo histórico e dialético.
\end{abstract}

PALAVRAS CHAVE: Educação Infantil. Desenvolvimento. Aprendizagem. Teoria histórico-cultural.

ABSTRACT: This research, based in historical-cultural theory, with a qualitative approach, look for understanding the teachers' concept about the child development of 1 to 3 years old children. The field research data were analyzed through open questionnaires with 14

\footnotetext{
${ }^{1}$ Graduada em Pedagogia da UNESC. lucianamacalossi@ hotmail.com

${ }^{2}$ Graduada em Educação Física, Mestra em Educação. UNESC. bcb@unesc.net
}

Saberes Pedagógicos, Criciúma, v. 4, nº 1, janeiro/abril 2020.- Curso de Pedagogia- UNESC 


\section{SABERES PEDAGÓGICOS}

Revista do Curso de Graduaçāo de Pedagogia - Unesc

ISSN 2526-4559

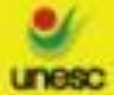

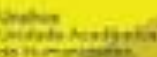

pedagogue teachers of the three childhood education center of the Municipality of Balneário Arroio do Silva / SC. The theme, "between the inatism and the learning: the child development concept the 1 to 3 years old children", aimed, in a descriptive way: 1) to understand the teacher researches' conception about development; 2) to identify the pedagogue teacher's perspectives about the relation between the 1 to 3 years old children development and learning and 3) to deepen the child development conception in the historical-cultural theory. The research results indicate that the teachers' understanding about the child development reflects, frequently, the inatism and the constructivism, in the different way from the curricular bases that guide the education system. Moreover, the analysis evidences the execution of a correlation between development and learning, which indicates a perception about its relevance. However, the majority of the teachers believe that the child needs to develop biologically before the learning. Therefore, this study, based in a historicalcultural theory, which emphasizes the importance of teach to de child development, evidences the organic relation between learning and development. It is understood, in this way, the child is active in the world, through a historical and dialectical process.

KEYWORDS: Childhood Education. Development. Learning. Historical-cultural theory.

\section{INTRODUÇÃO}

A presente pesquisa, ancorada na teoria histórico-cultural de Lev Semenovich Vygotsky $^{3}$ (1896-1934) e seguidores, objetiva se aproximar da compreensão que as professoras pedagogas do município de Balneário Arroio do Silva possuem sobre o desenvolvimento infantil de crianças de 1 a 3 anos de idade.

A escolha do tema surge da curiosidade de compreender a teoria históricocultural, assim como da experiência de uma das pesquisadoras no trabalho realizado como auxiliar de creche. Ao vivenciar a rotina da Educação Infantil, observou-se que o tempo dispensado ao cuidado, à higiene e à alimentação ${ }^{4}$ ganhava primazia frente aos aspectos do ensino. Além disso, ao observar o comportamento das crianças em suas ações com brinquedos, objetos e brincadeiras, o interesse da referida pesquisadora em saber o que as crianças são capazes de realizar e aprender nesse determinado período do seu desenvolvimento aumentava. Instigava-nos, ademais, compreender o que as professoras

\footnotetext{
${ }^{3} \mathrm{O}$ nome de Lev Semenovich Vigotski será preservado seguindo as referências de cada edição da literatura utilizada na fundamentação teórica.

Saberes Pedagógicos, Criciúma, v. 4, nº 1, janeiro/abril 2020.- Curso de Pedagogia- UNESC
} 
pedagogas podem ensinar e como as crianças podem aprender, ou seja, perceber como as crianças de 1 a 3 anos de idade podem ser ensinadas, tendo por objetivo o desenvolvimento de suas funções psicológicas superiores.

A compreensão acerca do desenvolvimento infantil é fundamental para a estruturação do trabalho pedagógico na Educação Infantil. Trataremos dessa questão, de modo mais aprofundado, no decorrer do artigo. Diante disso, neste estudo, buscamos compreender as concepções das professoras pedagogas em relação ao conceito de desenvolvimento infantil, com ênfase na primeira infância. Partindo desse interesse, a problemática desta pesquisa representa-se a partir do seguinte questionamento: qual a concepção das professoras pedagogas dos centros de educação infantil do Municipio de Balneário Arroio do Silva sobre o desenvolvimento infantil de crianças de 1 a 3 anos de idade. Tem-se, pois, como objetivo geral: analisar qual a concepção das professoras pedagogas dos centros de educação infantil do Município de Balneário Arroio do Silva sobre o desenvolvimento infantil das crianças de 1 a 3 anos de idade. Nesse sentido, elencamos como objetivos específicos: 1) compreender a concepção de desenvolvimento infantil das professoras pesquisadas; 2) identificar, na perspectiva das professoras pedagogas, a relação entre desenvolvimento e aprendizagem das crianças de 1 a 3 anos de idade e 3) aprofundar, com base na teoria histórico-cultural, a compreensão sobre o desenvolvimento infantil de crianças de 1 a 3 anos de idade.

Este trabalho busca, na teoria histórico-cultural ${ }^{5}$, pressupostos e fundamentos do desenvolvimento infantil na compreensão de que o ser humano se desenvolve socialmente, em um movimento histórico, cultural e dialético. Desse modo, acredita-se que a teoria históricocultural contribui para o trabalho pedagógico com as crianças pequenas, considerando a criança como ser ativo e atuante no mundo, que se desenvolve sob a influência das condições de vida e de educação, em correspondência com o meio social e a intervenção organizadora do adulto.

\footnotetext{
${ }^{4}$ Consideramos o educar e cuidar fundamentais, sendo que é indispensável ir além dessa dicotomia. É importante ressaltar o planejamento das atividades com intencionalidade na rotina diária das crianças, sem dispensar a função do cuidado.

${ }^{5}$ Sabemos que a teoria histórico-cultural é a base dos documentos legais que organizam os currículos escolares, como também, a proposta pedagógica do Estado de Santa Catarina.
}

Saberes Pedagógicos, Criciúma, v. 4, nº1, janeiro/abril 2020.-Curso de Pedagogia- UNESC 


\section{O INATO E O APRENDIDO: AFIRMAÇÃO DO CAMPO CONCEITUAL DA PESQUISA}

Partimos do pressuposto de que, para uma qualificada organização do ensino, independentemente do segmento abordado, é importante a compreensão dos processos de desenvolvimento humano, entendendo desenvolvimento e aprendizagem como conceitos entrelaçados. Essa vinculação é compreendida e defendida por distintas bases teóricas. Tais teorias são exemplos de como a sociedade, ao longo dos tempos, compreende o desenvolvimento humano a partir dos avanços possíveis desenvolvidos por diversas ramificações da ciência.

Por muito tempo, o ensino foi caracterizado por abordagens tradicionais. $\mathrm{Na}$ Educação Infantil, podemos indicar a dúvida constante das/os pedagogas/os sobre o paradigma de antecipação da escolarização dos pequenos ou a afirmação de determinado espontaneísmo na organização da rotina em sala de aula, o qual se caracteriza pela preocupação em manter o tempo da criança ocupado na escola, independentemente da forma e com que conteúdo se dará essa ocupação.

Portanto, a teoria histórico-cultural acredita que o professor deve conhecer o desenvolvimento humano e as características da criança para desenvolver objetivos que contribuam na organização do ensino e elevem suas potencialidades (FACCI, 2016). Para isso, faz-se necessário reafirmarmos a relação orgânica estabelecida entre psicologia e pedagogia, compreendendo as implicações sobre a organização do ensino na escola. Segundo Pasqualini (2016, p. 43), essa relação é vista da seguinte forma:

\footnotetext{
A psicologia, por si mesma, não é capaz de orientar a ação docente. Psicologia e pedagogia constituem uma unidade que orienta a prática pedagógica. O psicólogo russo S. L. Rubinstein, citado por Davidov (1988), analisa as relações entre psicologia e pedagogia afirmando que o que para uma é objeto, para outra é condição. Considerando a natureza histórico-cultural do desenvolvimento psíquico da criança, podemos dizer que o processo pedagógico é condição para que esse desenvolvimento aconteça. Ao mesmo tempo, considerando que os processos pedagógicos intervêm sobre diferentes níveis do desenvolvimento psíquico da criança, o desenvolvimento dos princípios que regem o desenvolvimento infantil é condição para seu planejamento.
}

Saberes Pedagógicos, Criciúma, v. 4, nº1, janeiro/abril 2020.- Curso de Pedagogia- UNESC 
A partir dessa concepção de que os princípios que regem o desenvolvimento infantil se colocam como condição para o planejamento do professor em cada nível de ensino, a seguir, traremos, brevemente, a reflexão acerca da periodização do desenvolvimento infantil na teoria histórico-cultural. Na sequência, direcionaremos a discussão para a atividade principal em relação à primeira infância, evidenciando a atividade objetal manipulatória.

\subsection{A periodização do desenvolvimento humano numa perspectiva histórico-cultural}

A teoria histórico-cultural, desenvolvida por um grupo de psicólogos soviéticos liderados por Lev Semenovich Vygotsky, data do século XX. Ao contrário das demais, a teoria histórico-cultural defende as relações sociais no desenvolvimento do psiquismo humano em relação orgânica com sua atividade, considerando, pois, que o homem está em constante aprendizado e desenvolvimento a partir das relações mediadas e construídas culturalmente.

O processo de desenvolvimento humano, nessa teoria, preconiza as ações da filogênese (desenvolvimento da espécie) e da ontogênese (desenvolvimento do homem), ou seja, compreende o homem como um ser histórico e social, que integra a cultura e a produz. Sendo assim, "o desenvolvimento ontogenético da psique é determinado pelos processos de apropriação das formas históricas e sociais da cultura.” (FACCI, 2016, p. 126). Esse processo, no entanto, não ocorre de forma natural e espontânea, mas a partir de uma mediação históricocultural.

O homem difere-se dos animais de maneira radical, uma vez que se humaniza nas relações sociais, ou seja, o homem é um ser social (PASQUALINI, 2016). Ademais, em situação de isolamento, ele não seria capaz de se apropriar das heranças sociais e culturais humanas. O homem transforma a natureza intencionalmente para satisfazer suas necessidades, e essa ação ocorre por meio do uso dos instrumentos e dos signos, salientando que o processo de transformação da natureza para a objetivação de objetos sociais é produto da atividade humana pelo trabalho (PASQUALINI, 2016). O desenvolvimento psíquico infantil, nessa perspectiva, está correlacionado com a atividade social desempenhada em cada momento histórico. Desse modo, cabe refletirmos acerca do papel ocupado pela criança. 
A mudança do lugar ocupado pela criança no sistema das relações sociais é a primeira coisa que precisa ser notada quando se tenta encontrar uma resposta ao problema das forças condutoras do desenvolvimento de sua psique. Todavia, esse lugar, em si mesmo, não determina o desenvolvimento: ele simplesmente caracteriza o estágio existente já alcançado. O que determina diretamente o desenvolvimento da psique de uma criança é a sua própria vida e o desenvolvimento dos processos reais desta vida - em outras palavras: o desenvolvimento da atividade da criança, quer a atividade aparente, quer atividade interna. Mas seu desenvolvimento, por sua vez, depende de suas condições reais de vida. (LEONTIEV, 2017, p. 63).

Ademais, a atividade humana é condição principal para o desenvolvimento humano. Segundo Leontiev (2017, p. 65), “a atividade principal é então a atividade cujo desenvolvimento governa as mudanças mais importantes nos processos psíquicos e nos traços psicológicos da personalidade da criança, em um certo estágio de seu desenvolvimento.” Por isso, a importância de compreender qual a atividade estará governando as funções psíquicas das crianças, as quais não são lineares e dependem da relação estabelecida com a realidade dos sujeitos. "É importante esclarecer que nem tudo o que o sujeito faz é atividade. A atividade humana é sempre movida por uma intencionalidade e busca responder a uma necessidade.” (TULESKI; EIDT, 2016, p. 45). Assim, as atividades principais caracterizam-se por três princípios: elas se constituem de outras formas de atividade, os processos psíquicos são reorganizados e dependem das principais mudanças da personalidade (LEONTIEV, 2017). As mudanças provocadas de um estágio ao outro dependem da relação particular entre atividade e ação (LEONTIEV, 2017). Em outras palavras, "o motivo da atividade, sendo substituída, pode passar para o objeto (o alvo) da ação, com o resultado de que a ação é transformada em uma atividade.” (LEONTIEV, 2017, p. 69).

Traçando relações com a pedagogia, uma questão errônea constantemente afirmada é a consideração de que o ensino precisa acompanhar a idade cronológica das crianças, corroborando uma percepção do desenvolvimento associada aos aspectos naturais, lineares e espontâneos do desenvolvimento infantil. Na perspectiva histórico-cultural, por sua vez, a aprendizagem é considerada como fator primordial para o desenvolvimento psicológico dos pequenos. Isso significa que a criança, de ser primitivo/biológico, avança em estágios históricos e culturais da conduta humana por meio do aprendizado das condições sociais presentes ao nascer.

Saberes Pedagógicos, Criciúma, v. 4, nº1, janeiro/abril 2020.- Curso de Pedagogia- UNESC 
Em suma, o desenvolvimento se produz por meio de aprendizagens e esse é o pressuposto vigotskiano, segundo o qual o bom ensino, presente em processos interpessoais, deve se antecipar ao desenvolvimento para poder conduzi-lo. Portanto, não há que se esperar desenvolvimento para que se ensine; há que se ensinar para que haja desenvolvimento. (MARTINS, 2012, p. 100).

Do mesmo modo, o foco de estudo de Vygotsky considerava os aspectos psicológicos do desenvolvimento infantil, enfatizando as funções psíquicas superiores. Essas funções, no curso do desenvolvimento humano, apresentam mudanças e rupturas complexas (neoformações) orientadas pelo período em que a criança se encontra e pela relação que ela estabelece com o meio (FACCI, 2016). Em outros termos, "o acesso ao desenvolvimento cultural e às elaborações humanas já produzidas socialmente pode intensificar ou dificultar o desenvolvimento humano das capacidades das crianças.” (FACCI, 2016, p. 127). Assim, o mundo humano é considerado o meio necessário para a apropriação dos significados culturais. Segundo Martins (2016, p. 14),

[...] o processo de aquisição das particularidades humanas, isto é, dos comportamentos complexos culturalmente formados, demanda a apropriação do legado objetivado pela prática histórico-social. Os processos de internalização, por sua vez, interpõem-se entre os planos das relações interpessoais (interpsíquicas) e das relações intrapessoais (intrapsíquicas), o que significa dizer: instituem-se baseados no universo de objetivações humanas disponibilizadas para cada indivíduo por meio da mediação de outros indivíduos, ou seja, por processos educativos.

Contudo, pensar a organização escolar na teoria histórico-cultural é conceber a aprendizagem e o desenvolvimento como processos unitários e estreitamente vinculados, que farão sentido se priorizarmos a relação intrínseca entre aprendizado e desenvolvimento pela zona de desenvolvimento proximal. A zona de desenvolvimento proximal é a distância entre o nível de desenvolvimento real já internalizado pela criança e o nível potencial das ações que estão em maturação, que demanda orientação de colaboradores mais capazes (VIGOTSKY, 2007).

Partindo disso, a criança irá se apropriar do mundo humano nas relações com as pessoas e com os objetos de conhecimento pela atividade mediada. Segundo Vygotsky (2007, p. 58) "todas as funções superiores originam-se das relações reais entre indivíduos humanos." De certa forma, o primeiro contato que a criança estabelece com o objeto é exploratório, sendo que, em um segundo momento, faz-se necessária a intervenção de um adulto mais

Saberes Pedagógicos, Criciúma, v. 4, nº1, janeiro/abril 2020.- Curso de Pedagogia- UNESC 
capaz para demonstrar as ações e operações a serem realizadas para que a criança internalize os significados e modos sociais de uso (PASQUALINI, 2016). Os seguidores de Vygotsky continuaram seus estudos na elaboração dos estágios da periodização do desenvolvimento infantil. Assim, Elkonin debruçou-se na explicação acerca das atividades principais atividade dominante ou atividade-guia, complexificando seus estágios e relacionando-os com possibilidades educativas no âmbito da formação humana.

Nesse sentido, a periodização do desenvolvimento humano na teoria históricocultural é vista como um processo histórico-dialético formado pela atividade principal e pelas neoformações ${ }^{6}$. "As neoformações, ou sínteses complexas das funções psíquicas, emergem da situação social em que a criança está inserida, a qual the exige determinadas reações." (TULESKI; EIDT, 2016, p. 53). Ou seja, ambas articulam-se sobre o lugar que os sujeitos ocupam nas relações sociais, desde a compreensão de que o homem é um ser social que se diferencia dos animais pela apropriação da cultura produzida por ele mesmo. Ademais, essa teoria não segue uma visão determinista evolutiva do desenvolvimento humano, mas considera a cultura como base para este processo por vias revolucionárias psíquicas. Desse modo, interessa, a esta pesquisa, elucidar a atividade principal das crianças de 1 a 3 anos de idade. O interesse maior do estudo centraliza-se nos aspectos da primeira infância, especificamente na atividade objetal manipulatória, apresentada brevemente na próxima sessão.

\subsection{Atividade objetal manipulatória: a atividade principal em dado período da primeira infância}

$\mathrm{O}$ nascimento representa o início da vida psíquica da criança em sua primeira crise, devido à transição intrauterina para extrauterina. A criança, nesse período, aprenderá a superar suas primeiras percepções do mundo a sua volta com os adultos que a acompanham. Esse primeiro período de vida é basicamente guiado por funções elementares simples (atenção e memória involuntárias) que se estenderá até mais ou menos um ano de idade. Nesse sentido,

\footnotetext{
${ }^{6}$ Implicações sobre homem e cultura no processo de hominização desenvolvida por Leontiev que poderá ser desenvolvida posteriormente.

Saberes Pedagógicos, Criciúma, v. 4, nº1, janeiro/abril 2020.-Curso de Pedagogia- UNESC
} 
é por meio da primeira atividade principal, denominada de atividade de comunicação emocional direta dos bebês com os adultos, que suas necessidades de sobrevivência são supridas: "embora o bebê dependa do adulto, ele ainda carece dos meios fundamentais de comunicação social em forma de linguagem.” (FACCI, 2004, p. 68).

Suas ações buscam recursos de comunicação pelo choro, pelo sorriso e pelo afeto que constrói com os adultos. Para Martins (2012, p. 106), "na etapa pré-linguística destacamse três momentos: o dos ruídos, dos murmúrios e balbucios e das pseudopalavras." Além disso, observa-se que, nessa etapa, a criança desenvolve o ato de agarrar e de preensão dos objetos. É, pois, no interior dessa primeira atividade, que a formação das ações sensóriomotoras de manipulação se desenvolve.

A vida da criança começa a ganhar novas formas de comunicação e manipulação dos objetos ou dos instrumentos sociais a partir do primeiro para o segundo ano de vida até o final do terceiro ano. Assim, o interesse da criança passa a ser outro nesse período. As ações sensório-motoras perceptivas abrem caminho para o significado social dos objetos de manipulação. Ademais, a criança já se locomove com mais facilidade na direção dos motivos de suas funções psíquicas superiores, como: atenção e percepção voluntárias, memória mediada e o pensamento abstrato, imaginação, sentimentos e emoções que conduzem modos culturais de comportamento (PASQUALINI, 2016).

Esse período também é marcado pela preponderante presença da linguagem, a qual irá movimentar as ações conscientes da criança-objeto-social, como também a formação de sua consciência e do seu "eu". Ou seja, a atividade objetal manipulatória gera um novo desenvolvimento psíquico: a linguagem entrelaçada com o pensamento (CHAVES; FRANCO, 2016). Em outras palavras, segundo Facci (2016, p. 135-136) "a função mais importante da linguagem, neste período, é ajudar a criança a compreender a ação dos objetos, é assimilar os procedimentos, socialmente elaborados, de ação com os objetos."

A importância da manipulação dos objetos não se deve ao fato do livre manuseio, mas está relacionada com o desenvolvimento da percepção infantil do instrumento de uso, carregado de significados e funções culturalmente elaboradas historicamente, a qual a ação mediadora do adulto propiciará. Ademais, o pensamento e a linguagem engendram a função social do signo, isto é, "a apropriação da linguagem irá duplicar o mundo perceptível,

Saberes Pedagógicos, Criciúma, v. 4, nº 1, janeiro/abril 2020.- Curso de Pedagogia- UNESC 


\section{SABERES PEDAGÓGICOS}

Revista do Curso de Graduaçāo de Pedagogia - Unesc

ISSN 2526-4559

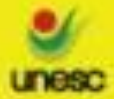

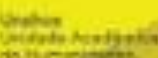

possibilitando à criança operar com os objetos na sua ausência para além das coisas observáveis e manipuláveis diretamente." (CHAVES; FRANCO, 2016, p. 115). Nesse processo, forma-se o pensamento sincrético ${ }^{7}$, pois o adulto atribui o significado do objeto por meio da linguagem mediada (CHAVES; FRANCO, 2016). Dessa forma, as pedagogas/os contribuem para que o ensino esteja organizado nos tempos e espaços que promovam a aprendizagem pela manipulação do objeto e pelo desenvolvimento da linguagem entrelaçada com o pensamento.

\section{METODOLOGIA, APRESENTAÇÃO E ANÁLISE DE DADOS}

Esta pesquisa, desenvolvida para esclarecer as dúvidas recorrentes quanto ao desenvolvimento e ao ensino de crianças pequenas, buscando seus fundamentos nos princípios da teoria histórico-cultural, caracteriza-se como de natureza básica e descritiva. Buscando responder a problemática deste estudo, acerca da concepção que as professoras pedagogas têm sobre o desenvolvimento infantil de crianças de 1 a 3 anos de idade, optou-se pela abordagem qualitativa. De acordo com Pinheiro (2010, p. 19), tal abordagem "considera que há uma relação entre o mundo real e o sujeito, isto é, um vínculo indissociável entre o mundo objetivo e a subjetividade do sujeito que não pode ser traduzido em números." Esses aspectos são favoráveis na interpretação das variáveis que indicam novas possibilidades de compreensão sobre a realidade estudada.

Desta forma, o procedimento metodológico utilizado para a coleta dos dados sobre as características ou fenômenos da realidade pesquisada ocorreu por meio de questionário aberto, contendo identificação profissional e 4 perguntas de caráter dissertativoargumentativo. A coleta dos dados foi realizada por uma pesquisa de campo nos 3 centros de educação infantil existentes no Município de Balneário Arroio do Silva. Antes de realizar a coleta dos dados, foi necessário entregar a carta de apresentação para o consentimento da pesquisa na Secretaria de Educação do Município de Balneário Arroio do Silva, para a diretora de ensino da secretaria de educação e para as diretoras/gestoras dos 3 centros de

\footnotetext{
${ }^{7}$ A criança nesse período atribui significados aos objetos de modo desordenado por meio de suas impressões subjetivas que o material externo lhe provoca.

Saberes Pedagógicos, Criciúma, v. 4, nº 1, janeiro/abril 2020.- Curso de Pedagogia- UNESC
} 
educação infantil. Conforme combinado com a diretora de ensino e com as diretoras das unidades, a coleta dos dados foi realizada com as professoras regentes de sala ${ }^{8}$ no período em que estavam em hora atividade, que é cumprida nas respectivas unidades onde trabalham. As professoras pedagogas regentes escolhidas para esta pesquisa atuam nas turmas de Berçário II, Maternal I e Maternal II, que correspondem às crianças de 1 a 3 anos de idade aproximadamente.

A coleta dos dados foi realizada entre os dias 27 e 31 de agosto/2018, nos turnos matutino e vespertino, com professoras pedagogas. O tema da pesquisa foi devidamente apresentado antes da assinatura do termo de consentimento. As professoras pedagogas o assinaram cientes do respeito às questões de ordem ética do estudo.

\subsection{Caracterização das professoras pedagogas}

A pesquisa, inicialmente, contemplava 23 professoras pedagogas, mas somente 14 responderam ao questionário e 9 não participaram da pesquisa ${ }^{9}$. Nesse sentido, para fins didáticos da pesquisa, as docentes participantes foram identificadas como PPA ${ }^{\mathbf{1 0}}, \mathbf{P P B}$, sucessivamente até a PPN. Todas são formadas em Pedagogia e estudaram nas respectivas instituições de ensino superior: UDESC, UNOPAR, UNIASSELVI e UNISUL. Ademais, 10 professoras pedagogas (A, C, E, F, G, I, J, K, M, N) são formadas nas seguintes instituições de especialização Latu Senso- Educação: FUCAP, UNOPAR, FSF, FAEL, FACEL, UNISUL e CENSUPEG. No Quadro 1, esses dados estão sistematizados, incluindo o tempo de atuação na área e o tempo na instituição de cada uma das participantes:

Quadro 1 - Sistematização dos dados referentes às participantes da pesquisa

\begin{tabular}{|c|c|c|c|}
\hline PEDAGOGA & FORMAÇÃO & TEMPO AT. NA ÁREA & TEMPO NA INST \\
\hline PPA & UDESC & 21 anos & 19 anos \\
\hline PPB & & Iniciando & 2 meses - ACT \\
\hline
\end{tabular}

\footnotetext{
${ }^{8}$ A escolha das professoras pedagogas regentes de sala se deu pelo fato de participarem ativamente no processo de planejamento e pelo tempo que as mesmas estão com as crianças no turno de cinco horas de trabalho.

${ }^{9}$ Três professoras pedagogas não entregaram o questionário no tempo previamente acordado. Duas professoras pedagogas não aceitaram participar da pesquisa. Quatro professoras pedagogas não puderam responder em sua hora atividade por motivos diversos.

${ }^{10}$ A abreviatura PP refere-se a professoras pedagogas mencionadas na análise dos dados.
}

Saberes Pedagógicos, Criciúma, v. 4, nº1, janeiro/abril 2020.-Curso de Pedagogia- UNESC 

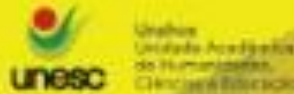

\begin{tabular}{|c|c|c|c|}
\hline PPC & \multirow{4}{*}{ UNOPAR } & 4 anos - APAE & 3 meses - ACT \\
\hline PPD & & Iniciando & $\mathrm{ACT}$ \\
\hline PPE & & 1 ano & 6 meses $-\mathrm{ACT}$ \\
\hline PPF & & & 3 anos - ACT \\
\hline PPG & \multirow{3}{*}{ UNIASSELVI } & 25 anos & 4 anos - Ef.etiva - ACT \\
\hline $\mathrm{PPH}$ & & 10 anos $-\mathrm{EF}^{11}$ & 1 ano/4 meses - Efetiva \\
\hline PPI & & 5 anos - Seg. Prof. EM ${ }^{12}$ & 1 ano/5 meses - Ef.etiva \\
\hline PPJ & \multirow{5}{*}{ UNISUL } & 4 anos & \multirow{4}{*}{4 anos - Efetiva } \\
\hline PPK & & 4 anos - digitadora & \\
\hline PPL & & Seg. Prof. EF & \\
\hline PPM & & 14 anos $-\mathrm{EF}$ & \\
\hline PPN & & 20 anos & 20 anos - Efetiva \\
\hline
\end{tabular}

Fonte: Dados da pesquisadora (2018).

Constatamos que 9 das professoras pedagogas são formadas em instituições de ensino semipresenciais e outras 5 no ensino presencial. Percebemos, além disso, que 5 das professoras pedagogas trabalham em outro seguimento escolar e, ainda, que uma delas exerce uma atividade profissional que não é a escola. Diante disso, quase $50 \%$ das professoras pedagogas necessita trabalhar no contra turno. Cabe refletir, desse modo, sobre o tempo dispensado para o planejamento das aulas e formação continuada. Para Raupp e Arce (2012, p. 74), "compreender a aprendizagem e o desenvolvimento das crianças é fundamental para o trabalho docente, é preciso saber como a criança se apropria dos conhecimentos, como ela explora o mundo." Compartilhando as ideias das autoras, percebeu-se que a formação das professoras pedagogas e sua prática reflexiva do cotidiano escolar irão apontar evidências de como o processo acadêmico de formação impactou na compreensão do desenvolvimento infantil.

\subsection{Aporte teórico das professoras pedagogas pesquisadas}

A primeira pergunta aberta presente no questionário direcionou-se para as obras ou livros utilizados, pelas professoras pedagogas, como suporte para o planejamento pedagógico. Entre as respostas obtidas ${ }^{13}$, destacaram-se 8 tipos de dados mencionados pelas

\footnotetext{
${ }^{11}$ A abreviatura EF refere-se ao Ensino Fundamental.

${ }^{12}$ A abreviatura EM refere-se ao Ensino Médio.

${ }^{13} \mathrm{Na}$ apresentação das respostas das professoras pedagogas foram consideradas, nas citações, a escrita na íntegra.
}

Saberes Pedagógicos, Criciúma, v. 4, nº1, janeiro/abril 2020.-Curso de Pedagogia- UNESC 
professoras pedagogas: projetos, coleções, internet, DVD/vídeo, documentos oficiais, livros didáticos, livros infantis/literatura e livros dos autores clássicos. Uma das participantes não respondeu a esta pergunta.

Quadro 2 - Sistematização dos suportes utilizados

\begin{tabular}{|c|c|c|}
\hline DADOS & QUANTIDADE & PROFESSORAS PEDAG. \\
\hline PROJETOS & 03 & PPC, PPG, PPI \\
\hline COLEÇÕES & $\mathbf{0 5}$ & PPJ, PPD, PPM, PPF, PPA \\
\hline INTERNET & 05 & PPD, PPC, PPE, PPH, PPA, \\
\hline DVD-VIDEO & $\mathbf{0 1}$ & PPJ \\
\hline DOCUMENTOS OFIC. & 03 & PPJ, PPK, PPN \\
\hline LIVROS DIDÁTICOS & $\mathbf{0 2}$ & PPL, PPF \\
\hline LIVROS INFANTIS/LITER. & 02 & PPG, PPI \\
\hline LIVROS AUT. CLÁS. & $\mathbf{0 1}$ & PPN \\
\hline
\end{tabular}

Fonte: Dados da pesquisadora (2018).

Verificou-se que o uso da internet aparece 5 vezes como suporte pedagógico. Isso demonstra que a internet se destaca como organizadora das atividades pedagógicas das professoras pedagogas desta rede de ensino, o que nos faz refletir sobre quais conteúdos estão sendo utilizados. Nesse sentido, cabe-nos destacar as bases de dados digitais como uma possibilidade qualificada de acesso a estudos que possibilitem a qualificação do planejamento pedagógico. Contudo, o que nos chama a atenção é a utilização exclusiva desse instrumento, descolada de referências qualificadas no processo de formação e ação pedagógica. Parece-nos que o planejamento pedagógico, mencionado aqui, esteja vinculado à seleção das tarefas a serem desenvolvidas pelas crianças.

A referência às coleções apareceu 5 vezes. As coleções indicadas pelas professoras pedagogas são de domínio particular ou da própria instituição. Esses materiais caracterizam-se por conterem conteúdo didático, ilustrações, planos de aulas, brincadeiras, etc. Outros dados que aparecem são os livros e os projetos da secretaria municipal. As respostas indicam a caracterização dos livros como livros infantis e livros didáticos, que são utilizados como referência pedagógica dos temas propostos nos projetos disponibilizados pela secretaria de educação. As respostas parecem indicar que, devido aos projetos que a secretaria repassa, as professoras pedagogas utilizam da literatura infantil para trabalhar temas relacionados aos eixos solicitados.

Saberes Pedagógicos, Criciúma, v. 4, nº1, janeiro/abril 2020.- Curso de Pedagogia- UNESC 
Ainda referente aos suportes utilizados, outro dado que aparece é o vídeo/televisão. Sabemos que a maioria das creches possui televisão, o que indica que as crianças assistem aos vídeos. Essa colocação nos faz pensar em que momentos e quais as intenções e finalidades são dispostas por meio deles. Analisando outros indicativos, 3 professoras pedagogas evidenciam a existência de documentos oficiais e autores clássicos que integram a formação acadêmica, mas não indicam seus títulos ou qual a contribuição dos autores em seu fazer pedagógico.

Para que a reflexão componha as discussões, precisamos questionar acerca da natureza do ser humano que a escola deseja formar, ou seja, qual a visão de homem, de mundo e de sociedade que a escola define em seu Projeto Político Pedagógico; quais são os objetivos e metas para se cumprir a aprendizagem na educação infantil; e, ainda, qual a concepção de ensino que dá conta de tamanha dimensionalidade.

Diante das respostas obtidas das professoras pedagogas, percebe-se um esvaziamento teórico na organização pedagógica na educação infantil de acordo com o segmento. Não fica evidente nas respostas se existe um documento norteador para a organização do ensino na rede. Entre as respostas das professoras pedagogas, verificaram-se diversos instrumentos, porém, em nenhuma delas, continha o Projeto Político Pedagógico como documento curricular, por exemplo. Ademais, os instrumentos descritos pelas professoras pedagogas, na maioria dos casos, não apresentam aporte teórico.

De acordo com Raupp e Arce (2012, p. 85),

\footnotetext{
Nesse sentido, novamente enfatiza-se a necessidade de as professoras de Educação Infantil irem para além do cotidiano em si, no exercício da sua função, e para isso, para a efetivação desse processo, é necessária uma sólida formação teórica que lhes forneça base para a compreensão do processo e dos desdobramentos da aprendizagem e do desenvolvimento da criança.
}

As indicações do aporte teórico apontados pelas professoras pedagogas e a reflexão das autoras contribuem para este trabalho à luz dos fundamentos da teoria históricocultural, que enfatizam o ensino com intenções e finalidades para as crianças pequenas. A partir das respostas das professoras pedagogas, observa-se que a organização do ensino parece seguir o interesse das crianças.

Saberes Pedagógicos, Criciúma, v. 4, nº 1, janeiro/abril 2020.- Curso de Pedagogia- UNESC 


\section{SABERES PEDAGÓGICOS}

Revista do Curso de Graduaçāo de Pedagogia - Unesc

ISSN 2526-4559

No mesmo sentido, a segunda pergunta buscava saber se as professoras pedagogas conheciam a existência de uma proposta pedagógica que orientasse a rede de ensino do Município de Balneário Arroio do Silva.

A PPF não respondeu a esta pergunta. As PPB, C, D, E, $\mathbf{M}$ e $\mathbf{H}$ responderam que não conhecem, somando o total de 6 que afirmaram não conhecer. Entre elas, uma resposta se colocou em evidência: "Não. No município no qual trabalho não há um Projeto Político Pedagógico, porém na instituição [...] na qual atuo há um Regimento Interno fundamentado na concepção sócio interacionista de Vygotsky, Wallon e Piaget." (PPN).

Por outro lado, 06 professoras pedagogas (PPJ, K, L, G, A e I), dizem que sim, conhecem. Porém, encontramos algumas contradições nas respostas. A PPJ respondeu que conhece. Mas, a PPK explicita: “Sim. A concepção pedagógica é a Histórico cultural de Vygotsky. Seguimos a proposta curricular do estado de santa Catarina." A PPL afirma também: "Sim. Cada instituição possui seu PPP, aqui orienta-se pelo PCN'S." Já a PPG descreve: "Sim. Sócio-interacionista de Vigotsky." A PPA também diz que "Sim. Sócio interacionismo (Vygotsky)."

Analisando os dados coletados sobre uma proposta pedagógica orientadora de ensino, alguns questionamentos se fazem pertinentes a essa questão, como o seguinte: De que forma estão organizadas as instituições de Educação Infantil na rede Municipal de Balneário Arroio do Silva? Outras reflexões se colocam, dentre elas, tem-se o questionamento de como a formação acadêmica inicial e as possíveis formações continuadas das docentes trataram a importância da organização do ensino. Estas reflexões, consequentes das respostas, poderão ser desenvolvidas posteriormente.

Ainda em relação à primeira pergunta, e também a segunda constata-se, além da diversificação e equívocos presentes nas respostas, uma incompreensão da importância de um documento norteador das ações pedagógicas. Isso, de fato, interfere na compreensão sobre o desenvolvimento infantil e de como agir no fazer pedagógico.

\subsection{O conceito de desenvolvimento}

Este tópico se coloca como central em relação à problemática desta pesquisa. Saberes Pedagógicos, Criciúma, v. 4, nº 1, janeiro/abril 2020.- Curso de Pedagogia- UNESC 
Questionamos as professoras pedagogas sobre o que compreendiam a respeito do conceito de desenvolvimento infantil. Os aspectos imediatos da maioria das respostas analisadas indicam uma concepção do desenvolvimento infantil como um processo de maturação biológica que ocorrerá de forma natural. Ou seja, a criança, primeiro, deve aguardar uma maturação biológica, respeitando sua idade em fases ou etapas, que levarão ao seu desenvolvimento. Segundo Leontiev (2017), percebe-se que o desenvolvimento da criança não se vincula de maneira direta ao estágio cronológico referente à idade, mas depende substancialmente do conteúdo da atividade que orienta a relação da criança com o mundo. Contudo, as respostas indicam que não há uma concepção elaborada de desenvolvimento. Ao que consta, há um conhecimento empírico sobre o assunto. Parece-nos que o conceito de desenvolvimento se apresenta de forma implícita nas respostas, mas carregadas de conceitos anteriormente construídos. Essa compreensão se reflete na maioria das respostas. A PPK descreve com maior evidência:

\footnotetext{
O conceito de desenvolvimento infantil está ligado ao período pelo qual todas as crianças passam desde o nascimento até aos 6 anos de idade mais ou menos, está ligado ao desenvolvimento de habilidades específicas, onde se espera das crianças alguns comportamentos, como por exemplo: o caminhar, as primeiras palavras. É um processo que garante a auto eficiência da criança. De acordo com Piaget as fases do desenvolvimento infantil. Observamos através de marcos: desenvolvimento físico, desenvolvimento cognitivo, desenvolvimento social e afetivo.
}

Essa resposta segue um pensamento de desenvolvimento relacionado ao construtivismo de Piaget, enfatizando que, para a criança aprender, ela precisará, primeiramente, aguardar até atingir o estágio de desenvolvimento. Ou seja, desenvolvimento e aprendizado teriam uma sequência de tempo cronológico atingido por estágios. Além disso, todas as crianças em uma mesma faixa etária estariam no mesmo nível de desenvolvimento mental, aguardando a idade biológica. Entretanto, com a teoria histórico-cultural é possível saber que, “[...] não é possível estabelecer estágios do desenvolvimento psicológico que se sucedam em uma ordem fixa e universal, válida para toda e qualquer criança em todo e qualquer contexto e a qualquer tempo.” (PASQUALINI, 2006, p. 117).

Na sequência das respostas, a PPJ descreve: "O desenvolvimento infantil consiste nas fases da criança que são: físico, intelectual, social e emocional.” A PPD também enfatiza os mesmos aspectos: "Acontece desde o nascimento até os 6 anos de idade. Durante essa Saberes Pedagógicos, Criciúma, v. 4, nº 1, janeiro/abril 2020.- Curso de Pedagogia- UNESC 


\section{SABERES PEDAGÓGICOS}

Revista do Curso de Graduaçāo de Pedagogia - Unesc

ISSN 2526-4559

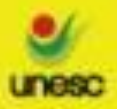

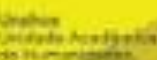

etapa, ocorre o desenvolvimento cognitivo, físico, social, afetivo.” Já a PPE explicita que é importante para o desenvolvimento integral da criança.

Percebe-se que as PP indicam esses aspectos como princípios do desenvolvimento infantil, mas não o relacionam com o desenvolvimento da criança no nível cognitivo. Ou seja, as respostas permitem inferir que, se não houver ensino, a criança irá atingir os aspectos citados da mesma forma, como se fosse algo natural e linear, ou atendendo aos princípios inatos das capacidades pela hereditariedade.

Na sequência das respostas, a PPG descreveu o desenvolvimento como uma “[...] evolução adequada a sua idade, tendo avanço em seu desenvolvimento." A PPH compreende o desenvolvimento infantil como um tempo/adaptação. As duas ideias colocam-se novamente como um processo maturacional biológico do organismo, sem interferência do meio, isto é, o desenvolvimento vai acontecer naturalmente.

De outro modo, a PPA, PPC, PPI e a PPM mencionam que o desenvolvimento é um processo que as crianças de 0 a 6 anos passam desde o nascimento. Em relação às respostas, pode-se dizer que a compreensão de desenvolvimento infantil das PP se relaciona com o conhecimento formado pela ideia de que a criança primeiramente se desenvolve em ordem cronológica, ou seja, demonstram evidencias da epistemologia genética de Piaget. Entretanto, a teoria histórico-cultural buscou superar o desenvolvimento condicionado somente pelos fatores biológicos (FACCI, 2016).

Outra resposta intrigante é mencionada pela PPF: “[...] Eu costumo dizer que são adultos em miniaturas, cada criança tem seu período diferenciado, alguns mais a frente outros num processo mais demorado." Defendemos que a criança é um ser histórico e, desde seu nascimento, está inserida nas relações culturais dispostas a sua volta. Considerar as crianças como adultos em miniaturas não condiz com a teoria histórico-cultural, isso porque, como citam as autoras Asbahr e Nascimento (2013, p. 420), “[...] a criança não é um adulto em miniatura. Há uma constituição infantil específica, tanto física como psicológica, que diferencia adultos e crianças não apenas quantitativamente, mas principalmente qualitativamente."

A PPN destaca “[...] é um processo natural, contínuo, dinâmico, único e progressivo [...] o desenvolvimento infantil consiste em uma sequência de etapas ou fases nas

Saberes Pedagógicos, Criciúma, v. 4, nº1, janeiro/abril 2020.- Curso de Pedagogia- UNESC 
que ocorre uma série de mudanças físicas, cognitivas, afetivas e psicológicas [...]” $\mathrm{O}$ desenvolvimento infantil, para Pasqualini (2006, p. 118), é um “[...] fenômeno histórico e dialético, não é determinado por leis naturais universais [...] e não se desenrola de forma meramente linear, progressiva e evolutiva, mas compreende saltos qualitativos, involuções e rupturas." O desenvolvimento irá percorrer cursos de novas formações por vias de evolução e revolução que se sobrepõe entre si provocando as crises (PASQUALINI, 2006).

Por fim, a PPL apresentou uma definição diferenciada das demais: "compreendo que é parte fundamental do desenvolvimento humano, onde a primeira infância conta como suporte para toda a vida adulta." De acordo, com Chaves e Franco (2016), é na primeira infância, entre os primeiros meses até aos 3 anos de idade, que ocorre a formação inicial da personalidade humana para que esta seja a base de todo o desenvolvimento posterior. Isso porque a criança muda biologicamente, mas se apropria do mundo a sua volta nas relações sociais em que está inserida, aprendendo sobre a cultura e de como agir sobre ela. Por isso, advogamos que, na primeira infância, a ação pedagógica deve se fazer presente, uma vez que as funções psicológicas superiores são produto de ordem social e não de uma maturação espontânea biológica (PASQUALINI, 2006).

Nesse sentido, a análise das respostas nos coloca a pensar sobre a perspectiva histórico-cultural que descontrói o determinismo biológico do desenvolvimento. Essa vertente psicológica não abandonou o problema da periodização do desenvolvimento (PASQUALINI, 2006). Preocupou-se em considerar o desenvolvimento não de maneira natural, seguida por fases previstas, e sim de caráter histórico e dialético, sendo influenciado pelo lugar que o indivíduo ocupa no conjunto das relações sociais (LEONTIEV, 2017).

\subsection{Relação entre desenvolvimento e aprendizagem}

A pergunta seguinte está voltada para a relação entre desenvolvimento e aprendizagem. Antecipadamente, 5 PP responderam que essa relação segue o curso natural/biológico do desenvolvimento. Por outro lado, 8 PP veem essa relação como indissociável e também destacam que a aprendizagem promove o desenvolvimento. Tomaremos para a discussão, primeiramente, os dados relacionados ao primeiro grupo citado.

Saberes Pedagógicos, Criciúma, v. 4, n¹, janeiro/abril 2020.- Curso de Pedagogia- UNESC 
Parece que a compreensão das participantes da pesquisa está associada à concepção de que a idade garante o desenvolvimento e não a atividade cognitiva mediada pela cultura humana, ou seja, a aprendizagem não faz parte desse primeiro processo. Agora, ao solicitar a relação entre o desenvolvimento e aprendizagem, temos respostas contraditórias. Pois, se para o desenvolvimento a concepção biológica está mais presente na relação desenvolvimento e aprendizagem, esta última se sobressai no primeiro aspecto. Sobre isso, Vigotsky (2007) explica que o aprendizado não é desenvolvimento, mas se o aprendizado for devidamente organizado ele resultará em desenvolvimento mental, movimentando outros processos de desenvolvimento, assim, o aprendizado é necessário no processo de desenvolvimento das funções superiores típicas humanas.

As PP que consideram a relação desenvolvimento e aprendizagem um fenômeno natural e da idade cronológica responderam: "Aprendizagem seria em que a criança aprende a andar e falar, já no desenvolvimento está relacionado ao tamanho e ao peso o corpo físico." (PPC). A PPF descreveu: "É um olhar diferente, porque a aprendizagem é algo natural, instantâneo. [...] Os desenvolvimentos são os estágios, as ações. [...]" Nessas respostas, concentra-se a ideia de que o ato de aprender é inato, bem como a necessidade de o desenvolvimento anteceder a possibilidade de aprender.

Outra resposta, da PPK, destaca a importância da família para que essa relação aconteça, afirmando que se deve conhecer a criança em todos os aspectos que ela apresentar. Além disso, destacou que são importantes os estímulos na garantia das habilidades. Conforme a teoria histórico-cultural, desde o nascimento a criança já esta aprendendo a sua volta e o afeto é essencial nesse processo. Contudo, a citação dos estímulos e habilidades nos remete à teoria empírica, a qual espera uma resposta da criança ao condicionar um estímulo.

A PPG escreveu: "Desenvolvimento é todo processo oferecido (permitido) ao aluno, onde ele possa demonstrar suas possibilidades, aprendizagem e o resultado do que foi oferecido." Para ela, o desenvolvimento terá que ser ensinado, e a aprendizagem é o resultado desse ensino. A PPI julgou que a relação entre os dois tem que estar de acordo e enfatizou que a criança deve ter qualidade na sua vida.

A relação entre desenvolvimento e aprendizagem deve seguir no pressuposto de que o aprendizado cria a zona de desenvolvimento proximal, impulsionado os processos

Saberes Pedagógicos, Criciúma, v. 4, nº1, janeiro/abril 2020.- Curso de Pedagogia- UNESC 
internos de desenvolvimento em interação com outras pessoas (VIGOTSKY, 2007).

Cabe, para o momento, direcionar-se para as respostas das 08 PP que citaram a relação entre desenvolvimento e aprendizado. A PPA menciona: "Eu creio que desenvolvimento e aprendizagem estão ligados desde o nascimento da criança e um não ocorre sem outro." A PPD, por sua vez, ressalta: "Os dois acontecem de forma conjunta na educação infantil." Já a PPE afirma: "Desenvolvimento e aprendizagem são dois conceitos que andam juntos, pois um precisa do outro para fazer sentido." A PPH diz, também, que um depende do outro. A PPJ escreve: "Em minha opinião o desenvolvimento da criança não pode ser visto de forma isolada em relação ao processo de aprendizagem.” E, por fim, a PPL reforça que "[...] são dois processos que acontecem quase concomitantemente, onde um precede ou sucede o outro, estando os dois processos ligados desde o nascimento da criança."

Destacam-se, em maioria, 06 respostas afirmando existir uma relação entre ambos, destacando a aprendizagem. Para esclarecer essa relação que é fundamental para o ensino, Asbahr e Nascimento (2013, p. 417) explicam:

\footnotetext{
Uma das importâncias em se estudar o processo de desenvolvimento humano está justamente em sua relação com a aprendizagem. As teorias sobre o desenvolvimento humano, através de suas explicações sobre o que se desenvolve no homem e como se desenvolve, delimitam as possibilidades de aprendizagem, ou seja, avaliam se ela pode ou não interferir nesse desenvolvimento e - sobretudo - como ela pode nele interferir.
}

Por isso, a teoria histórico-cultural enfatiza a relação entre o desenvolvimento e a aprendizagem, mantendo as questões educacionais como base para seus estudos, porque o desenvolvimento humano não ocorre sem o ensino (ASBAHR; NASCIMENTO, 2013). A crítica de Vigotski direcionava-se para as crenças de outras teorias de que a escola só poderia ensinar quando a criança atingisse certo nível de maturação. Para a teoria histórico-cultural, o desenvolvimento infantil segue o movimento histórico e dialético. Segundo Vygotsky (2017, p. 98), "o estado de desenvolvimento mental de uma criança só pode ser determinado se forem revelados os seus dois níveis: o nível de desenvolvimento real e a zona de desenvolvimento proximal."

A resposta da PPM destaca essa relação como: "De forma interligada. As vivências, interações e aprendizagens das crianças vão acontecendo integralmente a seu Saberes Pedagógicos, Criciúma, v. 4, nº 1, janeiro/abril 2020.- Curso de Pedagogia- UNESC 
desenvolvimento desde o nascimento das crianças.” (PPM). A PPN explicita, também, que:

Em minha opinião, a aprendizagem e o desenvolvimento possuem uma relação complexa e interligada, pois é a aprendizagem que fornece o desenvolvimento e esse não tem como acontecer sem que exista a aprendizagem. Ambos dizem respeito as aprendizagens do sujeito diante de suas interações com o mundo.

Corroborando com as pesquisadas ${ }^{14}$, observa-se que o alcance do desenvolvimento pela aprendizagem só será possível pela apropriação da cultura humana mediada pelos instrumentos e signos já produzidos historicamente. Por isso, a escola, o ensino e o professor são fundamentais no processo de aprendizagem, porque a intenção pedagógica irá promover o desenvolvimento.

Por isso, afirmamos que é indispensável fundamentar ações pedagógicas que qualifiquem e potencializem a formação humana e sua emancipação, em vista do seu desenvolvimento, pela apropriação do mundo humano a partir da relação que a criança estabelece com os objetos e com as pessoas que convive.

\section{CONCLUSÃO}

A realização da presente pesquisa buscou, na teoria histórico-cultural, fundamentos teóricos que objetivaram a aproximação da compreensão que as professoras pedagogas do Município de Balneário Arroio do Silva possuem sobre o desenvolvimento infantil de crianças de 1 a 3 anos de idade.

Os resultados da pesquisa permitiram concluir que as professoras pedagogas compreendem o desenvolvimento infantil nas concepções inatistas e construtivistas. Ademais, essas concepções reduzem a aprendizagem e elevam o desenvolvimento biológico, ou seja, para elas o desenvolvimento infantil ainda é reconhecido por concepções pedagógicas naturalizantes. Além disso, diante da análise entre desenvolvimento e aprendizagem, evidenciou-se a aprendizagem em sua relevância, mas as professoras pedagogas apontaram que o desenvolvimento biológico da criança deve anteceder ao aprendizado.

\footnotetext{
${ }^{14}$ Se faz necessário em estudos posteriores aprofundar os aspectos citados diferenciando os aspectos teóricos com mais detalhamento.

Saberes Pedagógicos, Criciúma, v. 4, nº1, janeiro/abril 2020.- Curso de Pedagogia- UNESC
} 
A teoria histórico-cultural enfatiza as questões educacionais em seus fundamentos e pressupostos, destacando a relação orgânica entre aprendizagem e desenvolvimento, na qual enfatiza o ensino sistematizado para o desenvolvimento psicológico das crianças de 1 a 3 anos de idade. Nesse sentido, o desenvolvimento infantil, nessa perspectiva objetiva o ensino para elevar suas potencialidades como sujeito ativo e atuante no mundo. A criança é considerada um ser atuante na sociedade pelo lugar ocupado por ela nas relações sociais presentes ao nascer, por meio de um processo histórico e dialético.

Por isso, é fundamental que as professoras pedagogas compreendam o desenvolvimento infantil para a estruturação do trabalho pedagógico. Como também, que a rede Municipal de Balneário Arroio do Silva compreenda a importância do Projeto Político Pedagógico como documento que fundamenta e organiza o ensino no ambiente escolar da Educação Infantil.

Este estudo só alimentou o desejo de qualificar o ensino da Educação Infantil com ações pedagógicas para a formação humana por meio da teoria histórico-cultural, a partir da relação que a criança estabelece com o mundo, com os objetos e com as pessoas que convive, destacando a importância das relações sociais no processo de apropriação da cultura humana. O estudo realizado provocou novas reflexões sobre a periodização do desenvolvimento infantil na primeira infância. Assim, surge a vontade de realizar novas pesquisas que aprofundem os aspectos da atividade objetal manipulatória em um possível estudo experimental.

\section{REFERÊNCIAS}

ASBAHR, Flávia da Silva Ferreira; NASCIMENTO, Carolina Picchetti. Criança não é manga, não amadurece: conceito de maturação na teoria histórico-cultural. Psicologia: ciência e profissão, Brasília, v. 33, n. 3, p.414-427, 2013.

CHAVES, Marta; FRANCO, Adriana de Fátima. Primeira infância: educação e cuidados para o desenvolvimento humano. In: MARTINS, Lígia Márcia; ABRANTES, Angelo Antonio; FACCI, Marilda Gonçalves Dias. (Org.). Periodização histórico-cultural do desenvolvimento psíquico: do nascimento à velhice. Campinas, SP: Autores Associados, 2016. p. 109-126. 


\section{SABERES PEDAGÓGICOS}

Revista do Curso de Graduaçāo de Pedagogia - Unesc

ISSN 2526-4559

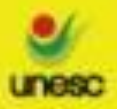

notionim

CHEROGLU, Simone; MAGALHÃES, Giselle. O primeiro ano de vida: vida uterina, transição pós-natal e atividade de comunicação emocional direta com o adulto. In:

MARTINS, Lígia Márcia; ABRANTES, Angelo Antonio; FACCI, Marilda Gonçalves Dias.

(Org.). Periodização histórico-cultural do desenvolvimento psíquico: do nascimento à velhice. Campinas, SP: Autores Associados, 2016. p. 93-108.

FACCI, Marilda Gonçalves Dias. A relação entre desenvolvimento e aprendizagem e a atuação do professor na educação infantil. In: PEIXE, Débora Cristina de Sampaio; BRAGAGNOLO, Regina Ingrid; CONDE, Soraya Franzoni. (Org.). Desafios e perspectivas da formação continuada de professores de educação infantil em Santa Catarina. Florianópolis, NUP/UFSC, 2016. p. 123-149.

A periodização do desenvolvimento psicológico individual na perspectiva de

Leontiev, Elkonin e Vigostski. Cad. Cedes. Campinas, v. 24, n. 62, p. 64-81, Abril, 2004.

LEONTIEV, Alexis N. Uma contribuição à teoria do desenvolvimento da psique infantil. In: VIGOTSKII, Lev Semenovich. (Org.). Linguagem, desenvolvimento e aprendizagem. Tradução de Maria da Pena Villalobos. 15. ed. São Paulo: Ícone, 2017. p. 59-83.

MARTINS, Lígia Márcia. O ensino e o desenvolvimento da criança de zero a três anos. In: ARCE, Alessandra; MARTINS, Lígia Márcia. (Org.). Ensinando aos pequenos de zero a três anos. 2. ed. Campinas, SP: Alínea, 2012. p. 93-121.

Psicologia histórico-cultural, pedagogia histórico-crítica e desenvolvimento humano. In: MARTINS, Lígia Márcia; ABRANTES, Angelo Antonio; FACCI, Marilda Gonçalves Dias. (Org.). Periodização histórico-cultural do desenvolvimento psíquico: do nascimento à velhice. Campinas, SP: Autores Associados, 2016. p. 13-34.

PASQUALINI, Juliana Campregher. Contribuições da Psicologia Histórico-Cultural para a educação escolar de crianças de 0 a 6 anos: desenvolvimento infantil e ensino em Vigotski, Leontiev e Elkonin. Dissertação (mestrado) - FAPESP - Fundação de Amparo à Pesquisa do Estado de São Paulo, Araraquara, 2006.

Concepção de ser humano, educação e desenvolvimento. In: PASQUALINI, Juliana Campregher; TSUHAKO, Yaeko Nakadakari. (Org.). Proposta pedagógica para a educação infantil. Secretaria Municipal de Educação de Bauru, 2016. p. 41-68.

PINHEIRO, José Maurício dos Santos. Da iniciação científica ao tcc uma abordagem para os cursos de tecnologia. Rio de Janeiro: Editora Ciência Moderna Ltda, 2010. 75 p.

RAUPP; Marilene Dandolini; ARCE, Alessandra. A formação de professores de educação infantil: algumas questões para se pensar a profissional que atuará com crianças de 0 a 3 anos. In: ARCE, Alessandra; MARTINS, Lígia Márcia. (Org.). Ensinando aos pequenos de zero a três anos. 2. ed. Campinas, SP: Alínea, 2012. p. 51-91. 
TULESKI, Silvana Calvo; EIDT, Nadia Mara. A periodização do desenvolvimento psíquico: atividade dominante e a formação das funções psíquicas superiores. In: MARTINS, Lígia Márcia; ABRANTES, Angelo Antonio; FACCI, Marilda Gonçalves Dias. (Org.).

Periodização histórico-cultural do desenvolvimento psíquico: do nascimento à velhice. Campinas, SP: Autores Associados, 2016. p. 35-61.

VIGOTSKY, Lev Semenovich. A formação social da mente. Tradução de Jose Cipolla Neto, Luís Silveira Menna Barreto, Solange Castro Afeche. 7. ed. São Paulo: Martins Fontes, 2007. $182 \mathrm{p}$. 